\title{
High Plasma Retinol-Binding Protein 4 Levels as Risk Factor of Type 2 Diabetes Mellitus in Abdominal Obesity
}

\author{
Anak Agung Gede Budhitresna, ${ }^{1 *}$ Ketut Suastika, ${ }^{1}$ Anak Agung Gede Budhiarta, ${ }^{1}$ Anwar Santoso ${ }^{2}$ \\ ${ }^{1}$ Endocrinology and Metabolism Division Department of Internal Medicine, \\ Faculty of Medicine Udayana University, Sanglah Hospital, Denpasar, Bali, Indonesia \\ ${ }^{2}$ Cardiology-Vascular Medicine Department, Faculty of Medicine Udayana University /Sanglah Hospital Denpasar, Bali, Indonesia
}

\begin{abstract}
Background. Abdominal obesity is a risk factor for cardiovascular disease and type 2 diabetes mellitus (T2DM). Plasma retinol-binding protein 4 (RBP4) levels have been reported to increase in the abdominally obese subjects and it has been hypothesized that high plasma protein levels were considered to play an important role in the occurrence of T2DM.
\end{abstract}

Objective. We assessed the value of high plasma RBP4 levels as risk factor of T2DM in abdominally obese subjects.

Methodology. A case-control study, nested within a cross-sectional study, on 81 abdominally obese subjects was performed. We studied 33 patients with T2DM, compared with 33 matched controls. The plasma RBP4 levels were measured by ELISA. Insulin resistance (IR) status of the patients were determined using HOMA-IR; $\beta$-cell function was determined using HOMA-B. Analysis of variance (ANOVA) was used to test the equality of continuous variables. Forward conditional logistic regression analyses were performed to examine the odds ratios (OR) between high plasma RBP4 levels and consequent T2DM. Path analyses models were performed to assess the influence of risk factors on occurrence of T2DM.

Result. Plasma RBP4 levels were significantly increased, while HOMA-B was significantly lower in cases with respect to controls. In analyses adjusted for multiple T2DM risk factors, we observed positive association with high plasma RBP4 levels $9.74(\mathrm{Cl} 95 \% ; 2.03-46.67)(p=0.004)$. It has been proven that high RBP4 level was a dominant risk factor $(66.9 \%, p=<0.001)$ influencing incidence of T2DM in the abdominally obese subjects.

Conclusion. The present study confirmed that high plasma RBP4 level is associated with increased incident T2DM in the abdominally obese subjects, and suggested that RBP4 has a major effect in the development of T2DM.

Key words: RBP4, Diabetes mellitus, Abdominal-obesity

\section{INTRODUCTION}

Abdominal obesity is strongly related to the pathogenesis of insulin resistance (IR) and T2DM. Adipose tissue may be viewed as an endocrine organ that secretes many types of adipokines (such as free fatty acid, tumor necrosis factor, interleukin-6, and adiponectin) that modulate the action of insulin and prothrombosis. ${ }^{1,2,3}$ Moreover, RBP4, a new fat-derived adipokine that specifically binds to retinol, has recently been reported to provide a link between obesity and IR. ${ }^{4}$ RBP4 was discovered while trying to identify the substance responsible for regulating insulin sensitivity in mice either lacking or overexpressing glucose transporter 4 GLUT4 in adipose tissue.5,6 It is regulated reciprocally in adipose tissue of mice overexpressing or lacking GLUT4. Circulating RBP4 levels were reported to be raised in several different mouse models of obesity and IR. ${ }^{4}$ Increasing the circulating levels of RBP4 leads to glucose intolerance, whereas knock-out of

e-ISSN 2308-118X

Printed in the Philippines

Copyright $(0) 2013$ by the JAFES

Received July 25, 2012. Accepted October 9, 2013. the RBP4 gene increases insulin sensitivity. ${ }^{4}$ Study on human, serum RBP4 levels correlated with the magnitude of IR in subjects with obesity, impaired glucose tolerance, or T2DM, and in non-obese, non-diabetic subjects with a strong family history of T2DM. ${ }^{7}$ Studies in abdominally obese patients have reported that plasma RBP4 level correlated with RBP4 $\mathrm{mRNA}^{8}$ and inflammation within adipose tissue. ${ }^{9}$ Despite this important scientific background and the inflammation risk associated with obesity, the relationship between plasma RBP4 levels and the risk of incident T2DM is unknown.

To address these issues, we evaluated the correlation between high plasma RBP4 levels with IR state and T2DM in a nested case-control study among abdominally obese subjects. Furthermore, we examined whether high plasma RBP4 levels can predict incident T2DM in addition to other risk factors.

Corresponding author: Anak Agung Gede Budhitresna, $M D, P h D$

Department of Internal Medicine, Udayana University/ Sanglah Hospital Jl.

Kesehatan no. 1, Sanglah, Bali, Indonesia

Tel. No.: $+62361-246274$

Fax No.: +62361-235982

E-mail:agbudhitresna@yahoo.com 


\section{METHODOLOGY}

We performed a nested-case control study among participants with abdominal obesity. The accessible subjects were recruited from the primary care clinics which provide universal health care at the Sanjiwani Hospital, Gianyar from October 2009 to February 2010. The study subjects were patients with abdominally obese (intended samples) selected from the accessible subjects that met the inclusion and exclusion criteria by using consecutive sampling technique. The actual study subjects were patients with abdominal obesity who had confirmed to be involved in this study by signing the informed consent according to the protocols approved by the ethics committees of Faculty of Medicine, Udayana University. Anthropometric status, included height, weight, and waist circumference (WC). Body mass index (BMI) was calculated as weight in $\mathrm{kg}$ divided by (height) ${ }^{2}$ in $\mathrm{m}^{2}$. Classification of weight by BMI and abdominal obesity by WC are determined according to the Asia-Pacific perspective redefining $\mathrm{BMI}$ and $\mathrm{WC}$ in adult Asians. ${ }^{30} \mathrm{BMI}$ classification was as follows: underweight $\left(<18.5 \mathrm{~kg} / \mathrm{m}^{2}\right)$, normal $\left(18.5-22.9 \mathrm{~kg} / \mathrm{m}^{2}\right)$, overweight at risk (BMI 23-24.9 $\left.\mathrm{kg} / \mathrm{m}^{2}\right)$, obese I (BMI $\left.25-29.9 \mathrm{~kg} / \mathrm{m}^{2}\right)$, and obese II (BMI $\geq 30$ $\left.\mathrm{kg} / \mathrm{m}^{2}\right)$, while the criteria for abdominal obesity were WC $\geq$ $90 \mathrm{~cm}$ in male and $W C \geq 80 \mathrm{~cm}$ in female. Diagnosis of diabetes mellitus was made either by the fasting and 2 hour-postprandial venous plasma glucose test. Subjects who were taking medication that can affect plasma glucose levels, positive family history in a first degree relative with T2DM, with coronary heart disease, chronic renal failure, chronic liver malfunction, infection, and malignancy were excluded. Patients who gave consent to join the study were informed about the study aims. Case ascertainment were patients having T2DM and controls were patients who remained free of T2DM. Attempts were made in order to match the case to each control by age (within 5 years).

A complete medical history, physical examination, collection of anthropometric and demographic data was performed in all subjects. The WC was measured at the midpoint between the lower costal margin and the iliac crest according to the World Health Organization's criteria. After an overnight fast of 8 hours, venous blood was obtained for plasma glucose, serum insulin, and lipid profile in all subjects. Blood pressure was measured for 3 consecutive readings in sitting position after the subjects rested for five minutes. The systolic and diastolic blood pressure was derived from an average of the three readings. Subjects were considered hypertensive if their office blood pressure was $\geq 140 / 90 \mathrm{mmHg}$. ${ }^{32}$

Plasma glucose was measured with the hexokinase method (Hitachi $912^{\circledR}$ ). Serum insulin was measured with chemiluminescence immunometric method (Immulite ${ }^{\circledR 2000)}$ with an intra and inter-assay coefficient of variation of $4.2-5.8 \%$. This assay does not have significant cross-reactivity with proinsulin. Serum levels of total cholesterol, high-density lipoprotein (HDL)cholesterol, triglycerides, and low-density lipoprotein (LDL)-cholesterol were measured on fresh samples with enzymatic method (Hitachi $912^{\circledR}$ ). Results were related to a standard consisting of commercially available (Roche Diagnostic $\mathrm{GmbH}$ ). Definition of dyslipidaemia is determined according to the IDF consensus definition of the metabolic syndrome in children and adolescents. ${ }^{31}$ Low HDL-cholesterol levels are defined as HDLcholesterol $<40 \mathrm{mg} / \mathrm{dL}$ in males and $<50 \mathrm{mg} / \mathrm{dL}$ in females, LDL- hypercholesterolemia is defined as raised LDLcholesterol $\geq 130 \mathrm{mg} / \mathrm{dL}$, and hypertriglyceridaemia is defined as raised triglycerides $\geq 150 \mathrm{mg} / \mathrm{dL}$. We measured plasma RBP4 using a commercially available ELISA kit (R\&D Systems, Inc., Minneapolis, United States of America). This assay can only detect human RBP4 and does not have significant cross-reactivity with other plasma components. It has a minimum detectable dose of $0.053-0.628 \mathrm{pg} / \mathrm{dl}$ with an intra and inter-assay variance of $7.0-8.1 \%$ and $7.3-8.6 \%$ respectively. Plasma TNF and TNF receptor 1 (TNFR1) were also measured using ELISA method (R\&D Systems, Inc., Minneapolis, United States of America). The cut-point to define high HOMA-IR, high RBP4 and high TNFR1 were determined base on the midpoint.

Insulin resistance and pancreatic beta cell function were calculated using the Homeostatic Model Assessment (HOMA) proposed by Matthews et al (10). The formulas are: Insulin resistance, HOMA-IR $=$ FPI $(\mu \mathrm{U} / \mathrm{ml}) \times$ FPG $(\mathrm{mmol} / \mathrm{L}) / 22.5$ and Beta cell function, HOMA- $\% \mathrm{~B}=20 \times$ FPI $(\mu \mathrm{U} / \mathrm{ml}) /[$ FPG $(\mathrm{mmol} / \mathrm{L})-3.5]$.

\section{Statistical Analysis}

Baseline characteristics were compared between cases and controls taking into account the matching between the two groups. Data were expressed as means \pm standard deviations. Statistical analysis was conducted using the Statistical Package for Social Science (SPSS) version 15.0. Group means were compared using paired Student's t-test where appropriate followed by post-hoc analysis. Homogeneity and normality of variances were assessed using the Levene's test and Kosmogorov-Smirnov's test, respectively. Correlation coefficient between RBP4 with various parameters were calculated using Pearson's correlation test. Odds ratios and corresponding 95\% confidence intervals (CI), as estimate of the relative risk of incident T2DM, were calculated using conditional logistic regression analysis. Adjustments for hypertension, fasting and 2 hour-postprandial plasma glucose levels, HOMA$\mathrm{IR}$, and HOMA-B were performed. A $p$ value of $<0.05$ was considered statistically significant. We also performed path analysis method to determine if there is a causaleffect between T2DM with multiple risk factors as TNF, TNFR1, RBP4, HOMA-IR, and HOMA-B. 


\section{RESULTS}

In linear regression analysis, there were significant factors influencing plasma RBP4 levels in subjects with abdominal obesity such as plasma TNFR1 levels, HOMA-IR, and HOMA-B respectively (data not shown). There were significant differences between cases and controls with respect to known $\mathrm{T} 2 \mathrm{DM}$ risk factors such as blood pressure, plasma lipid concentrations, HOMA-IR, HOMAB, plasma RBP4 levels, plasma TNF levels, and plasma TNFR1 levels (Table 1). Higher blood pressure, plasma lipid concentrations, HOMA-IR, HOMA-B, plasma RBP4 levels, plasma TNF levels, and plasma TNFR1 levels were observed in cases compared with controls. Plasma RBP4 levels were higher in cases than in controls (Table 1).

\section{Table 1. Baseline characteristics of study subjects}

\begin{tabular}{|c|c|c|c|}
\hline & $\begin{array}{c}\text { Cases }(n=33) \\
\text { Mean } \pm S D\end{array}$ & $\begin{array}{c}\text { Controls } \\
(n=33) \\
\text { Mean } \pm \text { SD }\end{array}$ & p \\
\hline \multicolumn{4}{|l|}{ Sex } \\
\hline $\begin{array}{l}\text { Men } \\
\text { Women }\end{array}$ & $42.00 \%$ & $\begin{array}{l}51.52 \% \\
48.48 \%\end{array}$ & $\begin{array}{l}0.475 \\
0.486\end{array}$ \\
\hline Weight $(\mathrm{kg})$ & $\begin{array}{l}58.00 \% \\
88.44 \pm 13.10\end{array}$ & $\begin{array}{l}48.48 \% \\
87.44 \pm 12.24\end{array}$ & $\begin{array}{l}0.406 \\
0.789\end{array}$ \\
\hline $\begin{array}{l}\text { Height }(\mathrm{cm}) \\
\text { Body mass index (BMI) }\end{array}$ & $\begin{array}{r}159.98 \pm 7.77 \\
34.46 \pm 4.19\end{array}$ & $\begin{array}{r}160.98 \pm 6.80 \\
33.65 \pm 3.45\end{array}$ & $\begin{array}{l}0.592 \\
0.405\end{array}$ \\
\hline Waist circumferences $(\mathrm{cm})$ & $103.92 \pm 8.06$ & $103.89 \pm 9.02$ & 0.990 \\
\hline Systolic BP (mmHg) & $142.94 \pm 24.62$ & $137.21 \pm 25.02$ & 0.409 \\
\hline Diastolic BP (mmHg) & $83.12 \pm 11.65$ & $78.96 \pm 13.73$ & 0.236 \\
\hline Hypertension & $51.52 \%$ & $12.12 \%$ & $<0.001$ \\
\hline Fasting blood sugar (mg/dl) & $197.76 \pm 59.04$ & $96.33 \pm 9.63$ & $<0.001$ \\
\hline $\begin{array}{l}2 \text { hours PP blood sugar } \\
(\mathrm{mg} / \mathrm{dl})\end{array}$ & $303.97 \pm 77.28$ & $119.91 \pm 23.87$ & $<0.001$ \\
\hline Total cholesterol (mg/dl) & $221.61 \pm 35.911$ & $212.64 \pm 39.65$ & 0.273 \\
\hline $\begin{array}{l}\text { Hypercholesterolemia } \\
(\mathrm{mg} / \mathrm{dl})\end{array}$ & $72.73 \%$ & $54.55 \%$ & 0.110 \\
\hline HDL - cholesterol (mg/dl) & $46.42 \pm 8.44$ & $45.67 \pm 6.56$ & 0.613 \\
\hline HDL- hypocholesterolemia & $33.33 \%$ & $36.36 \%$ & 0.768 \\
\hline LDL - cholesterol (mg/dl) & $146.24 \pm 33.38$ & $132.73 \pm 28.56$ & 0.071 \\
\hline LDL-hypercholesterolemia & $63.60 \%$ & $54.50 \%$ & 0.309 \\
\hline Triglycerides (mg/dl) & $169.97 \pm 65.65$ & $164.42 \pm 78.64$ & 0.739 \\
\hline Hypertriglyceridemia & $57.58 \%$ & $54.55 \%$ & 0.786 \\
\hline $\begin{array}{l}\text { Total cholesterol / HDL } \\
\text { ratio }\end{array}$ & $6.53 \pm 8.63$ & $4.73 \pm 1.05$ & 0.247 \\
\hline Insulin $(\mu \mathrm{lU} / \mathrm{ml})$ & $7.85 \pm 3.59$ & $7.69 \pm 5.13$ & 0.877 \\
\hline HOMA-IR & $3.70 \pm 2.18$ & $1.84 \pm 1.33$ & $<0.001$ \\
\hline HOMA-B (\%) & $22.87 \pm 13.99$ & $75.69 \pm 43.33$ & $<0.001$ \\
\hline RBP4 ( $\mu \mathrm{g} / \mathrm{ml})$ & $76.08 \pm 16.84$ & $41.13 \pm 14,75$ & $<0.001$ \\
\hline TNF (pg/ml) & $15.22 \pm 4.48$ & $11.18 \pm 5.25$ & 0.004 \\
\hline TNFR1 (ng/ml) & $5.88 \pm 2.75$ & $4.15 \pm 1.54$ & 0.005 \\
\hline \multicolumn{4}{|c|}{$\begin{array}{l}\text { Notes: TNF = tumor necrosis factor, TNFR1 = tumor necrosis factor } \\
\text { receptor 1, HOMA-IR = homeostasis model assessment insulin } \\
\text { resistance, HOMA-B = homeostasis model assessment beta cell } \\
\text { function. }\end{array}$} \\
\hline
\end{tabular}

Characteristic differences between cases compared to controls, there were several variables that potentially confounded effects on the relationship between plasma RBP4 levels and incident T2DM (Table 1). Multiple regression analysis was conducted using forward conditional logistic regression to evaluate the association of high plasma RBP4 levels as a risk factor for T2DM. Most interesting was that after adjustment for any significant T2DM risk factor, there was still an association between high plasma RBP4 levels and incident T2DM (Table 2). The odds ratios for incident T2DM of high plasma RBP4 levels was 9.74 (95\% CI $=2.03-46.67)$ compared with the lowest plasma RBP4 levels $(\mathrm{p}=0.004)$.
Table 2. Multiple logistic regression models of incident T2DM according to RBP4

\begin{tabular}{llccc}
\hline Variables & & $\begin{array}{c}\text { Adjusted } \\
\text { odds ratios }\end{array}$ & Cl 95\% & p \\
\hline 1. Model 1 & a. HOMA-IR & 6.92 & $(2.24-21.37)$ & 0.001 \\
& b. Constant & 0.07 & & 0.001 \\
2. Model 2 & a. HOMA-IR & 8.86 & $(2.48-31.63)$ & 0.010 \\
& b. TNF & 6.34 & $(1.84-21.83)$ & 0.003 \\
& c. Constant & 0.008 & & 0.000 \\
3. Model 3 & a. HOMA-IR & 8.38 & $(2.10-33.42)$ & 0.003 \\
& b. RBP4 & 9.74 & $(2.03-46.67)$ & 0.004 \\
& c. TNF & 9.73 & $(2.36-40.11)$ & 0.002 \\
& d. Constant & 0.000 & & 0.000 \\
\hline & & & &
\end{tabular}

The present study confirms that T2DM was a dependent variable, while plasma TNF levels, plasma TNFR1 levels, HOMA-IR, HOMA-B, and plasma RBP4 levels were independent variables. However, only HOMA-IR directly influenced consequent T2DM, whereas other variables were influenced indirectly through other risk variables. In path analysis model, plasma RBP4 level was the most dominant and consistent risk factor $(66.9 \%, \mathrm{p}<0.001)$ to consequent T2DM among abdominally obese subjects. The high plasma RBP4 levels were influenced both directly and indirectly through negative effect on HOMA-B and positive effect on HOMA-IR (Figure 1).

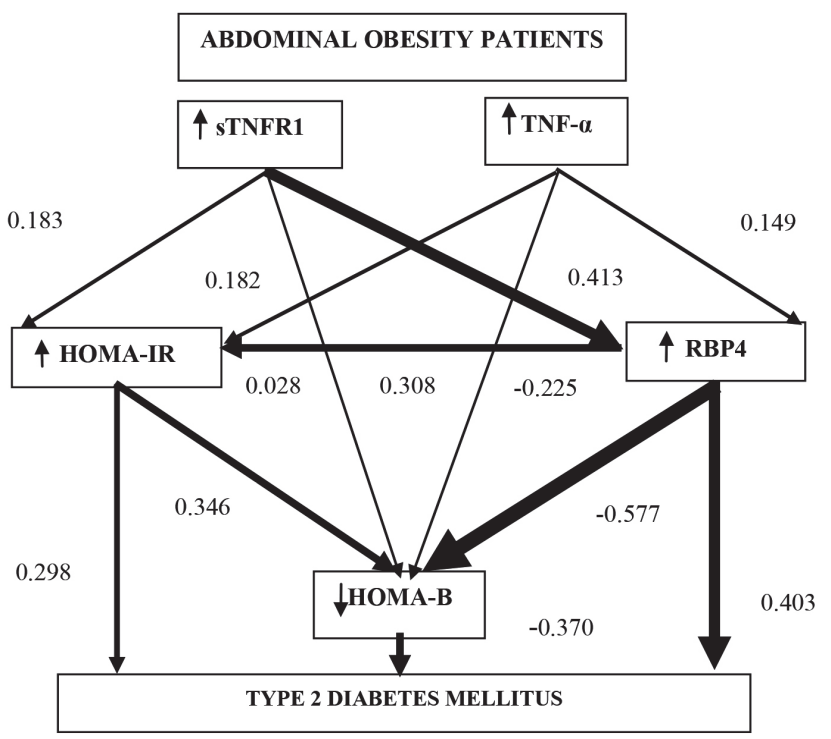

Figure 1. Overall, the study results could be summarized as follows: plasma RBP4 level as a risk factor was consistently the most important risk factor of incident T2DM, both directly and indirectly by increasing the risk of T2DM through HOMA-IR and HOMA-B. The extent of the risk factors' role on T2DM were represented by the line thickness.

\section{DISCUSSION}

TNF will activate adipokine expression change which is involved in the occurrence of IR and T2DM in abdominally obese patients through inflammatory signaling. ${ }^{7}$ An increases of RBP4 expression from adipose tissue and liver is influenced by TNF. ${ }^{9}$ We found a positive 
correlation between plasma TNF levels and plasma RBP4 levels. Therefore, there is an indication that abdominally obesity is correlated with the increase of adipose tissue inflammatory response which is positively associated to the increase of plasma RBP4 levels. Plasma RBP4 level in blood circulation is influenced by the quantity of abdominal fat. When abdominal fat is decreased, this then leads to the decrease of RBP4 levels. ${ }^{11,29}$ Other researchers have reported that circulating RBP4 levels were not associated with RBP4 expression in adipose tissue. ${ }^{12}$ Our findings also showed no correlation between waist circumference and plasma RBP4 levels. We cannot explain the molecular origin of the differences in our study. This difference may be due to the use of different polyclonal antibodies and different methods for protein detection (ELISA in our study and ELISA or Western blotting in other reports) and it must be recognized that our study population is more homogenous in terms of age, sex composition, and size of WC.

Examination of TNF system activity based on TNF receptor concentration will be more reliable, considering that this protein is easy to be recognized in the plasma and further, illustrate the degree of TNF system activity. ${ }^{13}$ The TNFR1 is a major mediator of TNF activity in the pathogenesis of IR and T2DM. ${ }^{14,} 15$ Activation of mitogenactivated protein kinase kinase kinase kinase 4 (MAP4K4) by TNF through TNFR1 would reduce the expression of PPAR $\gamma$ and GLUT4 in the adipocyte. ${ }^{16,17}$ The decreases in GLUT4 expression would interfere with the glucose transport in adipose tissue, which then stimulated the increased expression of RBP4. ${ }^{18}$ In this study, we found a significant positive correlation between plasma TNFR1 levels with high plasma RBP4 levels. The increase in RBP4 expression in abdominally obese was correlated with the occurrence of IR in adipose tissue. The increase of this plasma RBP4 levels is then going to cause disruption in signaling skeletal muscle insulin accompanied by stimulation of liver glucose production. ${ }^{9}$ In abdominally obese patients, the high plasma RBP4 levels correlated significantly with the degree of IR (measured by using the HOMA-IR). Thus, it seems that there is a positive link between adipose tissue inflammation with the increased expression of RBP4, which is associated with the occurrence of IR.

A significant negative correlation between high plasma RBP4 levels and beta cell secretion in abdominally obese patients was found in this study (measured by using the HOMA-B). This correlation can be the basic background for the association between the increased RBP4 in plasma with the incidence of T2DM. Pathophysiologically, retinol correlated with beta cell function. Circulating RBP4 forms bonds with transthyretin (TTR) protein, which is a functional component of the increase of beta cell secretion. ${ }^{19}$ Circulating TTR in humans binds strongly to RBP4. This can prevent TTR effect on beta cell secretion. ${ }^{20}$ Obtained data above imply that abdominally obese patients could not adapt to the low level of insulin sensitivity in the decreased insulin secretion.

In the present study, plasma RBP4 levels in T2DM subjects were significantly higher than in non-T2DM subjects. The high plasma RBP4 levels in T2DM subjects may be related to the degree of obesity and IR.21 Moreover, our study for the first time demonstrates that subjects with high plasma RBP4 levels have greater risk of developing T2DM ( $p=$ 0.004). Previously, many studies have reported a significant correlation between plasma RBP4 levels with the development of T2DM. However, these studies did not report how much of the plasma RBP4 levels influence the consequent occurrence of T2DM. ${ }^{22,23}$

Type 2 diabetes mellitus constitutes a group of metabolic disorders which are complex and heterogeneous. This results from a combination of IR and reduced secretion of beta cell. ${ }^{24}$ Beta cell failure was caused by low concentration of adiponectin and high plasma TNF levels. Indeed, these different levels are associated with increases of diabetes risk, which is also related to insulin sensitivity and pancreatic cell function. ${ }^{25}$ Our study demonstrates that plasma TNF level could not be proven as a risk factor for the development of T2DM. In obesity related T2DM, circulating levels of TNF are low, suggesting that TNF may mediate paracrine and autocrine signals. It is suspected that TNF endocrine effects were mediated by TNFR1, which are caused by decreases of expression of PPAR $\gamma$ and GLUT4 in adipose tissue.23 The decreased GLUT4 expression causes IR within adipose tissue, this subsequently stimulates RBP4 expression. ${ }^{4}$ This process likely occurs in abdominally obese patients, where it has been demonstrated that plasma TNFR1 levels affected the incidence of T2DM indirectly through RBP4 and HOMAIR. RBP4 injection in normal mice will lead to IR, while the paralyzed rat have an increase of RBP4 in insulin sensitivity. ${ }^{4}$ This study proved that high plasma RBP4 levels have positive influences on HOMA-IR. On the other hand, this protein was proven to give a negative impact on HOMA-B. Thus, it seems that negative influence of RBP4 to HOMA-B is not associated with IR. ${ }^{27}$ IR state is an important risk factor for T2DM, although it is not the central pathologic process of the disease. Beta cell dysfunction and apoptosis are important risk factors, which is likely that RBP4 is correlated with IR and beta cell function. ${ }^{27,} 28$ High plasma RBP4 levels showed statistical significance correlated with consequent T2DM through a positive effect on HOMA-IR and negative effect on HOMA-B.

The present study has limitations. The small sample size and a single measurement of RBP4 level at baseline does not rule out the possibility of variation of this parameter over time. Moreover, identification of other T2DM risk factors less completely and exclusion of undiagnosed T2DM for a prolong period may have underestimated absolute events. 


\section{CONCLUSION}

The present study confirmed that high plasma RBP4 levels were significantly correlated with T2DM, and suggested a major effect of RBP4 in the development of T2DM.

\section{Acknowledgement}

The authors gratefully acknowledge Prof. Mantik Astawa, DVM, Ph.D, chairman of the Department of Veterinary Laboratory, University of Udayana, Denpasar, for allowing us to identify all samples. The authors declared that there was no conflict of interest regarding this article.

\section{References}

1. Rajala M.W, Scherer P.E. Mini review: The Adipocyte - At the Crossroads of Energy Homeostasis, Inflammation, and Atherosclerosis. Endocrinology. 2003; 114 (9): 3765-73

2. Ronti T, Lupattelli G, Mannarino E. The endocrine function of adipose tissue: an update. Clin Endocrinol. 2006; .64: 355-65

3. Bastard J.P, Maachi M, Lagathu $C$ et al. Recent advances in the relationship between obesity, inflammation and insulin resistance. Eur Cytokine Netw. 2006; 17: 4-12.

4. Yang Q, Graham TE, Mody $\mathrm{N}$ et al. Serum retinol binding protein 4 contributes to insulin resistance in obesity and type 2 diabetes. Nature. 2005; 436: 356-62.

5. Abel ED, Peroni O, Kim JK et al. Adipose-selective targeting of GLUT4 gene impair insulin action in muscle and liver. Nature. 2001: 409: 729-33.

6. Shepherd PR, Kahn BB. Glucose transporters and insulin actionimplications for insulin resistance and diabetes mellitus. N Engl J Med. 1999; 341: 248-57.

7. Graham TE, Yang Q, Blüher $M$ et al. Retinol-Binding Protein 4 and insulin resistance in lean, obese, and diabetic subjects. $\mathrm{N}$ Engl J Med. 2006; 354: 2552-63.

8. Klöting N, Graham TE, Berndt J et al. Serum retinol-binding protein is more highly expressed in visceral than in subcutaneous adipose tissue and is a marker of intra-abdominal fat mass. Cell Metab. 2007; 6: 79-87.

9. Yao-Borengasser AW, Varma V, Bodles AM et al. Retinol Binding Protein 4 expression in humans: Relationship to insulin resistance, inflammation, and response to Pioglitazone. J Clin Endocrinol Metab. 2007; 92: 2590-97.

10. Matthews DR, Hosker JP, Rudenski AS et al. Homeostasis model assesment: Insulin resistance and beta-cell function from plasma glucose and insulin concentration in man. Diabetologia. 1985; 28: 412-19.

11. Lee J-W, Im J-A, Lee H-R et al. Visceral adiposity is associated with serum retinol binding protein-4 in healthy women. Obesity. 2007; 15: 2225-32.

12. Janke J, Engeli S, Boschmann $\mathrm{M}$ et al. Retinol-binding protein 4 in human obesity. Diabetes 2006; 55: 2805-10.

13. Zahorska-Markiewicz B, Janowska J, Olzanecka-Glinianowicz M et al. Serum concentrations of TNF- $\alpha$ and soluble TNF- $\alpha$ receptors in obesity. Int J Obes. 2000; 24: 1392- 95.

14. Uysal KT, Weisbrock SM, Hotamisligil GS. Functional analysis of tumor necrosis factor (TNF) receptors in TNF- $\alpha$-mediated insulin resistance in genetic obesity. Endocrinology. 1998; 139: 4832-38.

15. Sethi, JK, Xu H, Uysal KT, Wiesbrock SM et al. Characterisation of receptor-specific TNF-alpha functions in adipocyte cell lines lacking type 1 and 2 TNF- $\alpha$ receptors. FEBS Lett. 2000; 469: 77-82.

16. Sugnami T, Tanimoto-Koyama K, Nishida J et al. Role of the Toll-like receptor 4/NF-kappa B pathway in saturated fatty acid-induced inflammatory changes in the interaction between adipocytes and macrophage. Arterioscler Thromb Vasc Biol. 2007; 27: 84-89.

17. Tesz G, Guilherme A, Guntur KVP et al. Tumor Necrosis Factor $\alpha$ $(\mathrm{TNF} \alpha)$ stimulates Map4k4 expression trough TNF $\alpha$ Receptor 1 Signaling to c-Jun and Activating Transcription Factor 2. J Biol Chem. 2007; 282: 19302-12.

18. Guilherme A, Virbasius JV, Puri V et al. Adipocyte dysfunctions linking obesity to insulin resistance and type 2 diabetes. Mol Cel Biol. 2008; 9: 367-77.
19. Refai E, Dekki N, Yang S-N et al. Transthyretin constitutes a functional component in pancreatic $\beta$-cell stimulus-secretion coupling. PNAS. 2005; 47: 17020-25.

20. Broch M, Vedrell J, Ricart $\mathrm{W}$ et al. Circulating Retinol-Binding Protein-4, insulin sensitivity, insulin secretion, and insulin disposition index in obese and non-obese subjects. Diabetes Care. 2007; 30: 180206.

21. Graham TE, Kahn BB. Tissue-specific alterations of glucose transport and molecular mechanism of inter-tissue communication in obesity and type 2 diabetes. Horm Metab Res. 2008; 39: 717-21.

22. Cho YM, Young BS, Lee $\mathrm{H}$ et al. Plasma Retinol-Binding Protein-4 concentrations are elevated in human subjects with impaired glucose tolerance and Type 2 Diabetes. Diabetes Care. 2006; 29: 2457-61.

23. Takebayashi, K, Suetsugu M, Wakabayashi S et al. Retinol Binding Protein-4 levels and clinical features of Type 2 Diabetes patients. J Clin Endocrinol Metab. 2007; 92: 2712-19.

24. Hajer GR, van Haeften TW, Visseren FLJ. Adipose tissue dysfunction in obesity, diabetes, and vascular diseases. Eur Heart J. 2008; 29: 2959-71.

25. Prentki M, Nolan CJ. Islet beta cell failure in type 2 diabetes. J Clin Invest 2006; 116: 1802-12.

26. Graham TE, Wason CJ, Blüher M et al. Shortcomings in methodology complicate measurements of serum retinol binding protein (RBP4) in insulin-resistant human subjects. Diabetologia. 2007; 50: 814-23.

27. Kahn SE, Hull RL, Utzschneider KM. Mechanisms linking obesity to insulin resistance and type 2 diabetes. Nature. 2006; 444: 840-46.

28. Esteve E, Ricart W, Fernandez-Real JM. Adipocytokines and insulin resistance. Diabetes Care 2009; 32: S362-67.

29. Tschoner A, Sturm W, Engl J et al. Retinol Binding Protein 4, visceral fat, and the Metabolic Syndrome: Effects of weight loss. Obesity 2008; 16: $2439-44$.

30. WHO Regional Office for the Western Pacific: The Asia-Pacific perspective: redefining obesity and its treatment. Manila, Philippines: World Health Organization; 2000.

31. Chobanian AV, Bakris GL, Black $\mathrm{H}$ et al. National High Blood Pressure Education Program Coordinating Committee. The Seventh Report of the Joint National Committee on Prevention, Detection, Evaluation, and Treatment of High Blood Pressure. JAMA. 2003; 289: 2560-72.

32. Alberti KGMM, Zimmet $P$, Shaw J. International Diabetes Federation: a consensus on Type 2 diabetes prevention. Diabet. Met. 2007; 24: 451 63. 